\title{
High Sensitive and Selective Hydrogen Phosphate ISFET Based on Polyvinyl Chloride Membrane
}

\author{
S. Hidouri, ${ }^{a, *}$ Z.M. Baccar, ${ }^{a}$ A. Errachid, ${ }^{b, c}$ and O. Ruiz-Sanchez ${ }^{d}$ \\ ${ }^{a}$ Nano-bioingenery group, National Institute of Research in Physics and Chemistry Analysis \\ (INRAP), 2020 Sidi Thabet, Tunisia \\ ${ }^{b}$ Laboratory of Nanobioingéniery-IBEC, Scientific Parc of Barcelone (PCB), Spain \\ ${ }^{c}$ Lab. of Analytical Sciences (LSA)-UMR 5180, Univ. Claude Barnard of (UCB) Lyon I, France \\ ${ }^{d}$ Laboratory of Electronic Faculty of Physics University of Barcelone (UB), Spain
}

Received January 20, 2015; accepted October 13, 2015

\begin{abstract}
The present work describes the preparation and characterization of polyvinyl chloride membrane doped with methyl-salin ionophore. This electrode was successfully used for selectivity and high sensibility of monohydroxiphosphate in aqueous solution. $1 \mu \mathrm{M}$ detection limit of mono-hydrogen phosphate was obtained by using dibutyl phthalate and o-nitrophenyl octyl ether-poly vinyl chloride membrane in dynamic solution. The co-existence of a large excess of salts did not interfere with the detection in case of onitrophenyl octyl ether-poly vinyl chloride membrane that maked this selective electrode more adequate for the monohydrogen detection. Also, a highly selective and sensitive dihydrogen phosphate sensor was fabricated by autoassembly of polyvinyl chloride into silicium nitride gate of ISFET.
\end{abstract}

Keywords: Phosphate sensor, Sensitive, Ionophore, PVC, ISFET.

\section{Introduction}

Ion-selective electrodes (ISEs) containing polymeric membranes, such as poly(vinyl chloride) (PVC), assumed to behave as organic liquids of high viscosity, are the most versatile and widely studied class of ISEs. In order to obtain highly selective ISEs on the basis of PVC membranes, suitable ionophores must be doped into these polymeric membranes. The importance of monitoring phosphate concentration levels spans all areas of science and technology. A system that can continuously and selectively detect phosphate levels in aqueous

\footnotetext{
* Corresponding author. E-mail address: hidourislah@yahoo.co.in
} 
solutions will find numerous applications such as environmental monitoring $[1,2]$, where the problem is caused in part by the leaching of inorganic phosphate from agricultural land into waterways. Since phosphorus is an essential mineral for the human body and all other living organisms, where the majority of phosphorous exists as phosphate monohydrogen or dihydrogen phosphate [3], it was well studied in biomedical research, clinical chemistry and pharmacology.

Moreover, due to the vital importance of phosphate ions monitoring in many biological, environmental and industrial systems, the development of an efficient monohydrogen phosphate-sensor for a continuous monitoring in time is required. In the past, many achieved studies described methods of functionnalization for phosphorous detection and demonstrated the importance of the use of suitable compatible ionophore in suitable membranes (polymeric or inorganic material) for the development of MHP-ISEs inducing adequate phosphate selectivity.

\section{Experimental}

\section{Apparatus}

ISFETs based on Silicium nitride gate material were supplied by the Centre Nacional de Microelectrònica (Spain). The manufacturing process is described elsewhere [5]. Each chip was mounted on a standard printed circuit board. After wire bonding, the chip and the copper conductors were covered with epoxy resin (Epo-tek H77, Epoxy Technology Inc.), leaving only the pH-sensitive area uncovered. The ISFET measurements were carried out by fixing the drain source current at $\mathrm{I}_{\mathrm{DS}}=100 \mu \mathrm{A}$ and the $\mathrm{V}_{\mathrm{DS}}$ at $0.5 \mathrm{~V}$. A double junction $\mathrm{Ag} / \mathrm{AgCl}$ reference electrode was used to compensate the interface potential change of the ISFET.

A simple flow manifold was designed for ISFET measurements under dynamic conditions. In order to implement the ISFET in the flow system, a specially designed flow-through assembly was used, as described in [5].

\section{Reagents}

Reagent grade o-nitrophenyl octyl ether (NPOE), dibutyl phthalate (DBP) and benzyl acetate (BA) hexadecyltrimethylammonium bromide (HTAB), hexadecylpyridinium bromide (HDPB), tetrahydrofuran (THF) were purchased from Aldrich Chemical Company and used as received. Milli-Q ultra pure water was used throughout.

All $1 \mathrm{mM}$ salt solutions were mainly prepared by the dissolution of crystal reagents in Milli-Q water.

\section{Synthesis of membrane and electrodes preparation}

Before deposition, a membrane solution was prepared by mixing polymer, plasticizer (Plastisol) and a low concentration of Molybden Salin Ionophore. The value of the critical micellar concentration of surfactant in water was $2.10^{-3}$ mol. $\mathrm{L}^{-1}$ at $298 \mathrm{~K}$. It was introduced at the same concentration in all prepared membranes. 
We have prepared three types of solution membranes based on various plasticizer NOPE, DBP and BA. They were prepared by dissolving $7.0 \mathrm{mg}$ of MS, $58 \mathrm{mg}$ of plasticizer, $33 \mathrm{mg}$ of PVC and $2 \mathrm{mg}$ of HTAB in $3 \mathrm{ml}$ of THF. The mixture was stirred until a clear solution was obtained. The resulting mixture was deposited over the gate of the ISFET using a drop stick and spreading the drop in the surface. The solvent was allowed to evaporate for at least 12 hours at room temperature, and a thin membrane was obtained. The ISFET was finally conditioned in $\mathrm{KH}_{2} \mathrm{PO}_{4}$ solution at $10^{-3} \mathrm{M}$ for 30 minutes and washed with Milli$\mathrm{Q}$ water before use.

\section{Potential measurements}

All measurements were carried out by dumping in $25 \mathrm{~mL}$ of Milli-Q water or interfering analyte solution at $25^{\circ} \mathrm{C}$ and under magnetic stirring, both sensitive ISFET and double junction $\mathrm{Ag} / \mathrm{AgCl}$ electrode. After 5 minutes of stabilizing phases in aqueous solution, we added proper volumes of Monohydrogen Phosphate or Dihydrogen Phosphate. The gate output voltage variation for the ISFET was recorded and analyzed by labview software.

All calibration graphs were obtained in this way by plotting the recorded gate of output potential variation.

The selectivity of the membranes was studied by replacing the analyte solution by the potential interferon, such as $\mathrm{NaNO}_{3}, \mathrm{Na}_{2} \mathrm{SO}_{4}, \mathrm{NaI}, \mathrm{NaBr}, \mathrm{NaSCN}$ and $\mathrm{NaCO}_{3}$ at $10^{-3} \mathrm{M}$ concentration. The separate solution method (SSM) was used in order to calculate the selectivity coefficient $\mathrm{s}\left(\mathrm{K}^{\mathrm{pot}}{ }_{\mathrm{pho}, \mathrm{j}}\right)$ as described in Eisenman equation [6].

\section{Results and discussion}

The responses obtained using the three different types of plasticizer indicate that the PVC-DBP shows the highest sensibility to MHP as well as the other prepared membranes. Fig. 1 shows response slopes of the prepared membranes to the $\mathrm{HPO}_{4}{ }^{2-}$. The obtained performance for PVC-DBP ISFET is a super Nernstian sensibility of $69.54 \mathrm{mV} /$ decade, from dynamic range of $3.010^{-5}$ to $3.010^{-2} \mathrm{M}$, and a detection limit less than $1 \mu \mathrm{M}$.

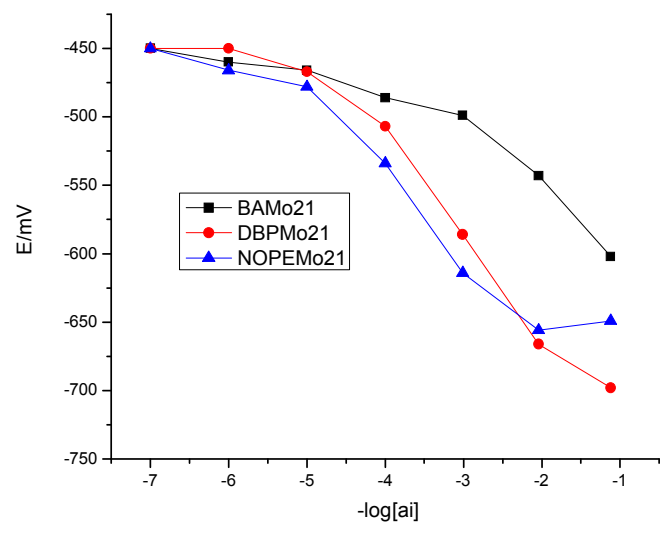

Figure 1. Calibration plots of MHP-ISFETs based on conducting polymer doped by MS. 


\section{Selectivity studies of sensors}

The selectivity of the membranes was studied by changing Milli-Q water solution with solutions containing potential interfering anions such thiocyanate, iodide, nitrate, bromide, sodium sulfate, and carbonate as described above. Representative response curves for interfering ions of the electrode based on PVC-DBP with MS are presented in Fig. 2 and their principle characteristics values (sensibility, dynamic range and detection limit) are resumed in Table 1. The high interfering anions are sulfate, nitrate and iode anions. However, $\mathrm{CO}_{3}{ }^{2-}$, $\mathrm{Br}^{-}$and $\mathrm{SCN}^{-}$are not significant interfering ions and their calculated potentiometric selectivity coefficients for MHP are less than 3. The Hofmeister selectivity sequence of the series of anion displayed by the PVC-DBP sensor is $\mathrm{HPO}_{4}{ }^{2-}>\mathrm{NO}_{3}{ }^{-}>\mathrm{I}^{-}>\mathrm{SO}_{4}{ }^{2-}>\mathrm{CO}_{3}{ }^{-}>\mathrm{Br}^{-}>\mathrm{SCN}^{-}$.

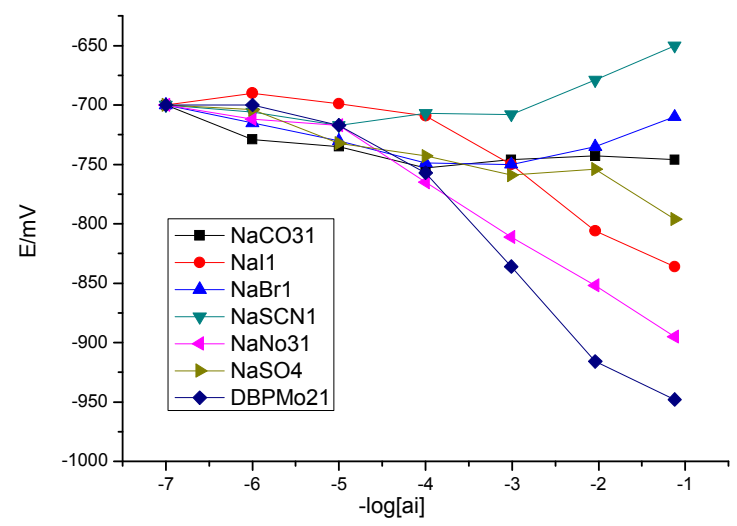

Figure 2. Interference curves of MHP selective PVC-DBP electrode.

Table 1. Detection limit of PVC-DBP electrode and interference effect for MHP anion.

\begin{tabular}{|l|c|c|c|c|c|c|c|}
\hline Analyte & $\mathrm{H}_{2} \mathrm{O}$ & $\mathrm{NaBr}$ & $\mathrm{NaCO}_{3}$ & $\mathrm{NaI}$ & $\mathrm{NaNO}_{3}$ & $\mathrm{Na}_{2} \mathrm{SO}_{4}$ & $\mathrm{NaSCN}^{-1}$ \\
\hline $\begin{array}{l}\text { Detection } \\
\text { limit (M) }\end{array}$ & $10^{-7}$ & $10^{-3}$ & - & $10^{-4}$ & $10^{-5}$ & $10^{-2}$ & $10^{-3}$ \\
\hline $\begin{array}{l}\text { Dynamic } \\
\text { range (M) }\end{array}$ & $\begin{array}{c}3.0 \times 10^{-5}- \\
3.0 \times 10^{-2}\end{array}$ & $10^{-2}-10^{-1}$ & - & $10^{-4}-10^{-2}$ & $\begin{array}{c}3.0 \times 10^{-5} \\
-10^{-1}\end{array}$ & $\begin{array}{c}10^{-2}- \\
3.0 \times 10^{-1}\end{array}$ & $\begin{array}{c}3.010^{-3} \\
-10^{-1}\end{array}$ \\
\hline $\begin{array}{l}\text { Slope } \\
\text { (mV/decade) }\end{array}$ & -69.5 & +23.0 & - & -48.9 & -44.5 & $(-72)$ & 30.5 \\
\hline $\begin{array}{l}\text { Selectivity } \\
\text { coefficient } \\
\left(\log \mathrm{K}_{\text {Pot }}^{\text {Pij }} \text { ) }\right.\end{array}$ & & -3.57 & -3.02 & -1.75 & -0.92 & -2.33 & -4.43 \\
\hline
\end{tabular}

Table 2. Detection limit of PVC-NOPE electrode and interference effect for MHP detection.

\begin{tabular}{|l|c|c|c|c|c|c|c|}
\hline Analyte & $\mathrm{H}_{2} \mathrm{O}$ & $\mathrm{NaBr}$ & $\mathrm{NaCO}_{3}$ & $\mathrm{NaI}$ & $\mathrm{NaNO}_{3}$ & $\mathrm{Na}_{2} \mathrm{SO}_{4}$ & $\mathrm{NaSCN}$ \\
\hline $\begin{array}{l}\text { Detection } \\
\text { limit(M) }\end{array}$ & $10^{-6}$ & $1.10^{-7}$ & $5.0 \times 10^{-5}$ & $3.10^{-5}$ & $1.10^{-6}$ & - & - \\
\hline $\begin{array}{l}\text { Dynamic } \\
\text { range (M) }\end{array}$ & $10^{-5}-10^{-2}$ & $\begin{array}{c}10^{-5}- \\
2.0 \times 10^{-2}\end{array}$ & $10^{-4}-10^{-1}$ & $10^{-4}-10^{-1}$ & $10^{-5}-10^{-2}$ & - & - \\
\hline $\begin{array}{l}\text { Slope } \\
\text { (mV/decade) }\end{array}$ & 58.9 & 36.08 & 8.00 & 43.87 & 33 & 0.00 & 0.00 \\
\hline $\begin{array}{l}\text { Selectivity } \\
\text { coefficient } \\
\text { (log K }\end{array}$ & & -1.80 & -2.95 & -1.43 & -1.51 & -3.53 & -4.07 \\
\hline
\end{tabular}


The study of the MHP-sensor based on PVC-NOPE doped membrane was carried out as shown in Fig. 3 and Table 2. In comparison with the performance described above, a lower super Nernstian response is observed $(58.9 \mathrm{mV} /$ decade for NOPE versus $69.5 \mathrm{mV} /$ decade for DBP) from $10 \mu \mathrm{M}$ to $10 \mathrm{mM}$ and $1 \mu \mathrm{M}$ of detection limit. The selectivity of this membrane was studied, and only $\mathrm{I}^{-}$and $\mathrm{B}^{-}$ may be considered as competitive interfering anions of MHP ions. However, responses of these anions were at least one lower order of magnitude than for MHP. The selectivity pattern for the series of anions displayed by PVC-NOPE electrode is $\mathrm{HPO}_{4}{ }^{2-}>\mathrm{I}^{-}>\mathrm{NO}_{3}{ }^{-}>\mathrm{Br}^{-}>\mathrm{SO}_{4}{ }^{2-}>\mathrm{CO}_{3}{ }^{-}>\mathrm{SCN}^{-}$(the three latest ions are no significant interfering anions).

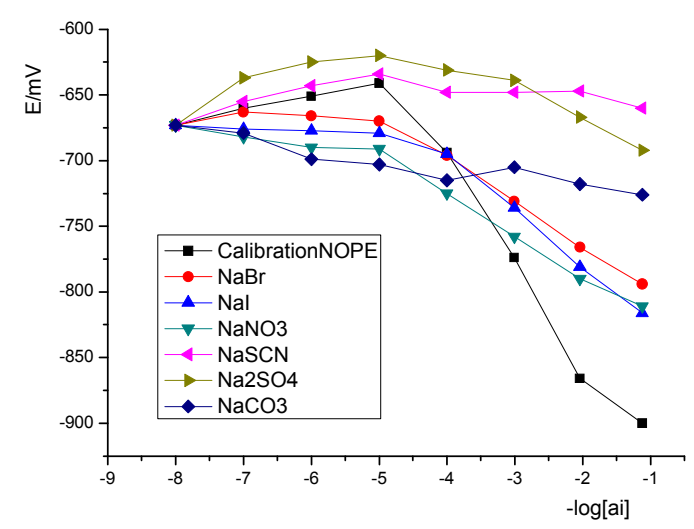

Figure 3. Interference curves in case of PVC-NOPE (MHP).

In the case of calibration by the $\mathrm{KH}_{2} \mathrm{PO}_{4}$ ions, as shown in Fig. 4, the more sensitive sensor is the PVC-BA electrode (Table 3). In fact, the PVC-BA sensor presents a near Nernstian slope to DHP ions $(51.8 \mathrm{mV} /$ decade between $0.1 \mu \mathrm{M}$ to $0.1 \mathrm{M}$ ), a detection limit lower than $0.1 \mu \mathrm{M}$. However, a sub-Nernstian sensibility of $19.1 \mathrm{mV} /$ decade between $3.010^{-4}$ and $10^{-1} \mathrm{M}$ was measured with NOPE membrane, while no significant response was obtained with the PVCDBP electrode.

Table 3. Detection limit of PVC-BA electrode for MHP detection.

\begin{tabular}{|l|c|}
\hline Analyte & $\mathrm{H}_{2} \mathrm{O}$ \\
\hline Detection limit(M) & $1.10^{-7}$ \\
\hline Dynamic range $(\mathrm{M})$ & $10^{-6}-10^{-3.5}$ than $\left(10^{-3.5}-10^{-1}\right)$ \\
\hline Slope (mV/decade) & 20.9 than $(46.2)$ \\
\hline
\end{tabular}

The selectivity study of DHP-sensor based on PVC-BA doped membrane was presented in Fig. 5 and the corresponding values are reported in Table 4. A suitable selectivity to the interfering anions was observed for concentrations lower than $1 \mathrm{mM}$. Only the PVC-BA electrode shows an interfering response to $\mathrm{NaCO}_{3}$ of $49.8 \mathrm{mV} /$ decade for a concentration higher than $0.3 \mathrm{mM}$. However, the selectivity coefficient is lower than -4.8. The low value of $K^{\text {pot }}{ }_{i j}$ indicates that the obtained response with $\mathrm{CO}_{3}{ }^{2-}$ should be considered as an interfering response. This is probably due to the variation of $\mathrm{pH}$ at high concentrations, as well as added to the increase of the ionic force of the analyte. 


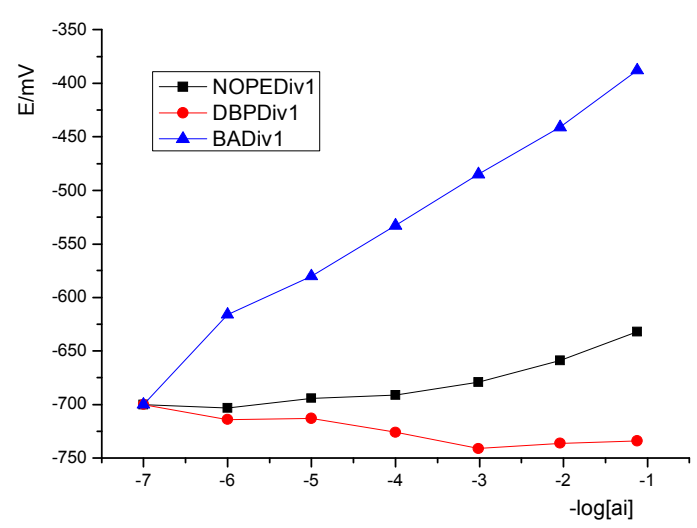

Figure 4. Calibration plots of DHP sensor.

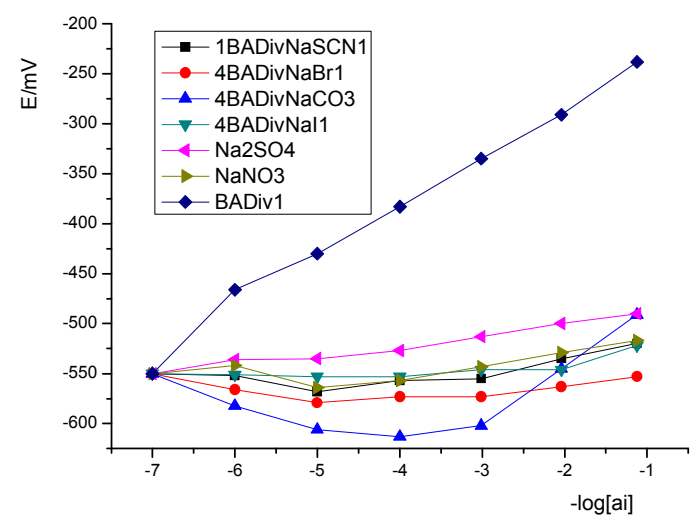

Figure 5. Interference curves of DHP-sensor based on PVC-BA membrane.

Table 4. Detection limit PVC-BA electrode and interference effect for DHP detection.

\begin{tabular}{|l|c|c|c|c|c|c|c|}
\hline Analyte & $\mathrm{H}_{2} \mathrm{O}$ & $\mathrm{NaBr}$ & $\mathrm{NaCO}_{3}$ & $\mathrm{NaI}$ & $\mathrm{NaNO}_{3}$ & $\mathrm{Na}_{2} \mathrm{SO}_{4}$ & $\mathrm{NaSCN}$ \\
\hline $\begin{array}{l}\text { Detection } \\
\text { limit (M) }\end{array}$ & $<10^{-7}$ & - & $10^{-4}$ & - & - & - & - \\
\hline $\begin{array}{l}\text { Dynamic } \\
\text { range (M) }\end{array}$ & $10^{-7}-10^{-1}$ & - & $\begin{array}{c}3.0 \times 10^{-4}- \\
10^{-1}\end{array}$ & - & - & - & - \\
\hline $\begin{array}{l}\text { Slope } \\
\text { (mV/decade) }\end{array}$ & +51.85 & - & +49.8 & - & - & - & - \\
\hline $\begin{array}{l}\text { Selectivity } \\
\text { coefficient } \\
\left(\log \mathrm{K}_{\text {Pij }}^{\text {ij }}\right.\end{array}$ & & -6.07 & -4.88 & -5.48 & -5.38 & -4.86 & -5.44 \\
\hline
\end{tabular}

In this study, we have observed that the Nernst constant increases in both MHP and DHP detection. This result may be due to the experimental conditions: the formation of redox entities of phosphate during measurements should amplify the signal responses. In fact, redox properties of the phosphate ion in aqueous solution depend on $\mathrm{pH}$ and the different forms of orthophosphate. Their distribution exists as following:

$$
\mathrm{H}_{3} \mathrm{PO}_{4} \stackrel{\leftrightarrows}{\leftrightarrows} \mathrm{H}_{2} \mathrm{PO}_{4}^{-} \leftrightarrows \mathrm{HPO}_{4}^{2-} \leftrightarrows \mathrm{PO}_{4}^{3-}
$$


In their turn, $\mathrm{H}_{2} \mathrm{PO}_{4}{ }^{-}$prevails in acidic condition and $\mathrm{HPO}_{4}{ }^{2-}$ is more predominant under basic conditions. Both forms of phosphate could be formed in $\mathrm{pH} 7$. Therefore, under neutral conditions, the slope of the sensor response can be used to indicate when the electrode is responding to the mono- or di-hydrogen phosphate anion [7].

\section{Life time study}

As shown in Fig. 6, the life time study of membranes shows that the PVC-DBP membrane presents a suitable stability of the response during the 4 days test. However, a decrease in sensitivity was observed after the verification of the probable mechanical damage of the membrane and of the probable infiltration of the aqueous solution between the gate of the transducer and the sensitive PVC film, or of the probable need to change the condition storage by immerging the sample in an $0.1 \mathrm{M} \mathrm{Na}_{2} \mathrm{HPO}_{4}$ solution like the conventional MHP-ISEs one.

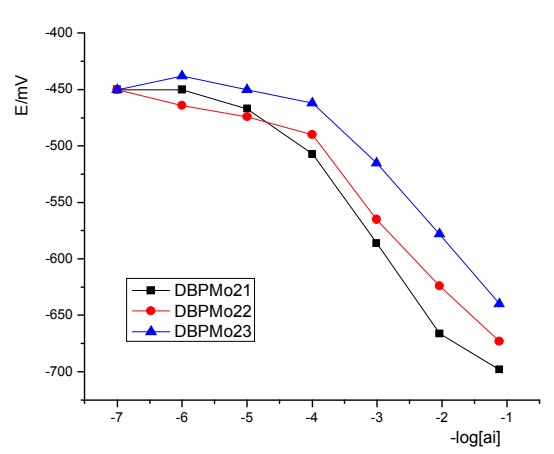

(a)

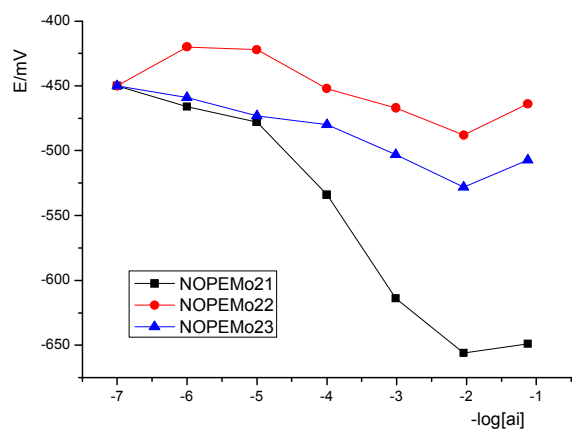

(b)

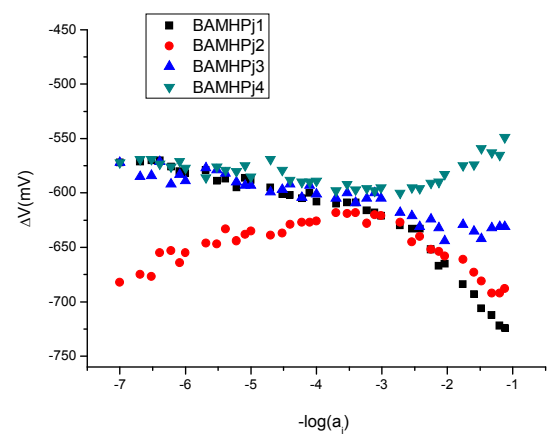

(c)

Figure 6. Life time of MHP-sensors based on: (a) PVC-NOPE membrane; (b) PVCDBP membrane; (c) PVC-BA membrane.

A similar decrease in sensitivity is observed with NOPE and BA-PVC membranes. The life time of these membranes is shorter than the PVC-DBP electrode. In fact, a significant decrease in the response is observed after the first day's measurement (respectively, the second day's testing), for PVC-NOPE (resp. PVC-BA) sensor. This result indicates the single use of PVC-NOPE electrode. However, the BA-PVC films are stable in the two first days of MHP measurement; then, a decrease in the sensibility is observed in the third day's test. However, the PVC-BA films show a response that was stable for more than 3 days when it was used for DHP detection. In fact, as shown in Fig. 7, the 
sensibility become stable after 3 days of continuous measurement with a lower decrease after the first day's measurement.

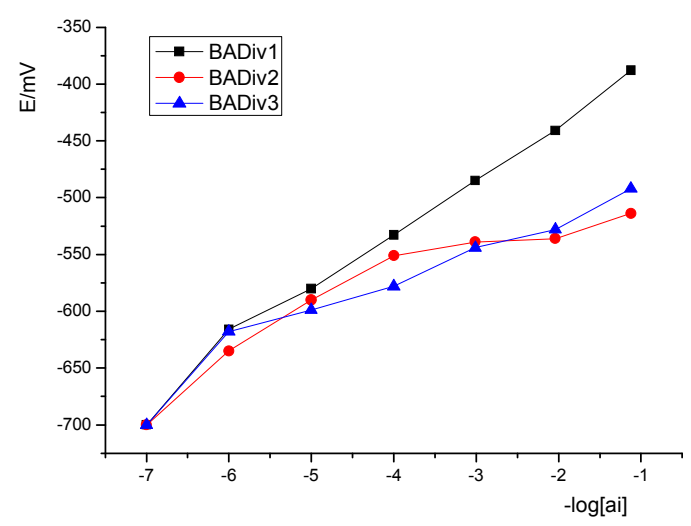

Figure 7. Life time of DHP-sensor based on PVC-BA membrane.

\section{Conclusions}

PVC DBP-based Ion-Sensitive Field Effect Transistor doped with MS ionophores can be considered as a good mono-phosphate $\left(\mathrm{HPO}_{4}{ }^{2-}\right)$ sensitive and selective sensor. A super-Nernstian response was obtained with a dynamic wide range from $3.010^{-5}$ to $3.010^{-2} \mathrm{M}$ of $\mathrm{HPO}_{4}{ }^{2-}$; the detection limit is less than $1 \mu \mathrm{M}$. However, a short life time of 4 daily measurements is obtained. In comparison to the performances described in literature, an amelioration of the detection limit was obtained with a PVC DBP membrane, and similar selectivity responses with commonly MHP-ISEs [8-11]. This decrease of the detection limit can be useful in food industry, environmental and water monitoring or pharmaceutical fields. The use of a plasticizer for the fabrication of phosphate sensors such as ISFET based on PVC membranes has several advantages for the development of nanotechnology for ionic detection.

In the present study we can conclude that the suitable plasticizer for the suitable entrapment of MS ionophore and monohydrogen phosphate detection is the PVC-DBP matrix. However, for the dihydrogen phosphate detection a suitable membrane is the PVC-BA which presents a good performance (a near Nernstian slope, a large dynamic range from $0.1 \mu \mathrm{M}$ to $0.1 \mathrm{M}$; a detection limit less than $0.1 \mu \mathrm{M}$ and highly selective). The obtained results should allow the possibility to elaborate a mobile system involving the monitoring of phosphate in many fields, such as in biomedical and environmental applications. However, the short lifetime of these sensors can be considered as their principle inconvenient, in particular for an environmental application. The optimization of the protocol for the membrane preparation and the investigation of new polymeric matrixes can resolve this limitation.

\section{Acknowledgment}

The authors would like to thank the Tunisian-Spain project AECI (A/9711/07). 


\section{References}

1. Robards K, McKelvie ID, Benson RL, et al. Determination of carbon, phosphorus nitrogen and silicon species in waters. Anal Chim Acta. 1994;287:147-190.

2. Worsfold PJ, Achterberg EP, Bowie AR, et al. Field-Based Analytical Techniques for Aquatic Environmental Monitoring. Chiang Mai J Science. 2003;30:153-164.

3. Shils M, Olsen JA, Shilke M, et al. Nutrition in Health and Disease. 9th ed. Baltimore: Williams and Wilkins; 1999.

4. Cane C, Gricia L, Merlos A, et al. Compatibility of ISFET and CMOS technologies for Smart Sensors. Proceedings 6th Int Conf Solid State Sensors and Actutors (Transducers' 91). San Francisco; 1991.

5. Jiménez C, Bartroli J. Development of an Ion-Sensitive Field Effect Transistor Based on PVC Membrane Technology with Improved LongTerm Stability. Electroanalysis. 2015;9:316-319.

6. Koryta J. Ion-Selective Electrode. Cambridge: Cambridge University Press; 1975.

7. Kivlehan F, Mace WJ, Moynihan HA, et al. Potentiometric evaluation of calix[4]arene anion receptors in membrane electrodes: phosphate detection. Analytica Chimica Acta. 2007;585:154-160.

8. Carey CM, Riggan WB. Cyclic Polyamine Ionophore for use in a dibasic phosphate selective electrode. Anal Chem. 1994;66:3587-3591.

9. Liu D, Chen W-C, Yang R-H, et al. Polymeric membrane phosphate sensitive electrode based on binuclear organotin compound. Anal Chim Acta. 1997;338:209-214.

10. Fibbioli M, Berger M, Schmidtchen FP, et al. Polymeric membrane electrodes for Monohydrogen Phosphate and sulfate. Anal Chem. 2000;72:156-160.

11. Kim J, Kang DM, Shin SC, et al. Functional polyterthiophene-appended uranyl-salophen complex: Electropolymerization and ion-selective response for monohydrogen phosphate. Anal Chimica Acta. 2008;614:85-92. 